\title{
La competencia partidista en las elecciones generales de 2015: factores contextuales y anclajes ideológicos
}

\author{
Irene Delgado \\ Universidad Nacional de Educación a Distancia, Madrid, España \\ idelgado@poli.uned.es
}

\begin{abstract}
Resumen: Este trabajo se sitúa en el contexto de los estudios electorales. Los cambios acontecidos en el escenario político español tras las elecciones generales de 2015 demandan un análisis de los factores individuales del voto que han guiado las orientaciones de los electores. Partiendo de un marco teórico explicativo general y con análisis de datos de encuestas del Centro de Investigaciones Sociológicas tratamos de aislar los determinantes de carácter contextual y el peso de los anclajes ideológicos que han orientado el voto a los principales partidos de ámbito estatal. Los resultados muestran que tanto los factores a corto plazo como factores estructurales han sido tomados en consideración por los votantes para apoyar a las formaciones políticas, generado una fuga de votos de los partidos tradicionales hacia las nuevas formaciones políticas, dentro de la estructura del marco ideológico.
\end{abstract}

Palabras clave: comportamiento electoral, partidos políticos, elecciones.

\begin{abstract}
In the context of electoral studies, this article explores the changes that took place in the Spanish political scene after the general elections of 2015. The analysis of the individual voting factors that guided the electoral behavior starts from a general theoretical framework, and examine survey data from the Center for Sociological Research. It tries to isolate the determinants of contextual characters and the weight of the ideological anchors that have dominated the vote for the main parties. The results show that combination of both the short-term factors and the long- term factors, where the ideology plays an important role, have conditioned the support to the new political formations generating an important change in the preferences of the voters but conditioned by the ideological framework.
\end{abstract}

Key words: electoral behavior, party politics, elections. 


\section{INTRODUCCIÓN}

Las elecciones generales de 2015 han supuesto un punto de inflexión en el escenario electoral español con amplias consecuencias en el sistema de partidos. La fragmentación de la competición política ha reflejado la inestabilidad de las preferencias electorales rompiendo la dinámica parlamentaria bipartidista, asentada hasta ahora, sobre una sólida concentración de votos y escaños entre las dos fuerzas mayoritarias. El curso de la legislatura y los acontecimientos advenidos fueron sin duda elementos que influyeron en este cambio de apoyo de los votantes a los partidos. Pero ¿qué ocurrió entre 2011 y 2015 que significó una pérdida, entre los dos partidos mayoritarios, de 83 escaños en el Congreso y una fuga de más de cinco millones de votantes? A lo largo de la II legislatura de Mariano Rajoy se jalonaron una serie de acontecimientos que fueron indicios suficientes para apuntalar un cambio en el comportamiento electoral de los españoles. Entre la opinión pública se percibieron valoraciones hacia el sistema político que más tarde se trasladarían a las orientaciones electorales. De hecho, se hicieron visibles a través de los resultados de las elecciones europeas de 2014 y de las elecciones autonómicas y municipales de 2015, que mostraron un debilitamiento de los anclajes de los votantes tradicionales y un incremento de la volatilidad electoral, permitiendo la entrada de nuevos actores políticos en la esfera institucional. Las elecciones generales de 2015 confirmaron el inicio de un nuevo ciclo electoral con repercusiones en la gobernabilidad del sistema político. No obstante, el nuevo sistema de partidos que se ha erigido no ha quebrado los espacios ideológicos de la izquierda y la derecha tan presentes en la política española. Estos espacios se han transformado, aunque siguen desempeñando un papel esencial en la orientación del comportamiento electoral. La entrada de un mayor número de fuerzas políticas en la competición electoral altera la distribución de la configuración de los bloques ideológicos reactivando un cambio sustantivo en la orientación electoral.

Hemos de considerar, además, que la identificación ideológica no es el resultado de un proceso psicológico individual o social, sino que es también producto del propio desarrollo del proceso político, desarrollo en gran medida definido por la competencia electoral entre partidos para conseguir el mayor número posible de votos, y en el que estos actores se convierten en los principales artífices — aunque no los únicos- de la conformación de las identidades políticas de los votantes. Junto con la ideología coexisten otros elementos de carácter contextual (o de corto alcance) que modifican o alteran el comportamiento de los electores en las sociedades democráticas actuales, dificultando los criterios explicativos a largo plazo. A nuestro juicio, en este trabajo sobre las elecciones generales de 2015 sostenemos que la orientación del voto ha estado guiada, 
de un lado, por la reestructuración de factores ideológicos y, de otro lado, por la evaluación de elementos coyunturales, lo que plantea un interesante análisis sobre la congruencia ideológico-electoral. A tenor de ello nos planteamos analizar el papel desempeñado por la ideología en los cambios electorales de los españoles en las elecciones de 2015, toda vez que elementos de carácter económico parecen haber sido relevantes sobre los resultados de elecciones precedentes. Tratamos de determinar si la ideología, anclaje electoral de carácter político, ha ejercido una influencia relevante sobre las orientaciones de los electores en 2015 y si este elemento de aparente estabilidad y amplia capacidad predictiva sobre el comportamiento electoral ha sufrido alguna transformación con la presencia de nuevos partidos políticos en el escenario electoral.

Este trabajo aborda en primer lugar un recorrido teórico por los diferentes modelos de voto que han explicado la formación de las identidades políticas de los ciudadanos a través de una serie de factores inmersos en el propio juego político, entre ellos el papel que desempeñan sobre la recreación de las identificaciones, las estrategias y los movimientos de los partidos en función de la dinámica que se deriva de la competencia electoral partidista. Este examen se llevará a cabo a partir del estudio de la significación y de la evolución de la configuración del esquema izquierda-derecha, en la medida que este constituye una de las formas más generalizadas de concebir y medir el establecimiento de vínculos con de los ciudadanos. A continuación, se realiza una descripción de los cambios asociados a los anclajes ideológicos de los electores como consecuencia del grado de incertidumbre electoral existente en la esfera política ante la entrada de nuevos partidos políticos, lo que permitirá valorar el éxito de sus estrategias en un escenario de alto nivel de competitividad. A través del análisis de los datos de encuestas procedentes del Centro de Investigaciones Sociológicas, se tratará de estimar el peso específico de la dimensión ideológica en el voto a los partidos respecto de otros factores explicativos de carácter coyuntural. Finalmente, presentamos algunas conclusiones y sugerencias para futuros análisis.

\section{APROXIMACIÓN TEÓRICA A LOS MODELOS DE VOTO}

Los modelos de comportamiento electoral han sido fundamentalmente desarrollados para explicar cómo los ciudadanos pueden ejercer el «no tan simple acto de votar» en un mundo político de enorme complejidad y que exige de ellos un esfuerzo considerable de recogida de información, comprensión y análisis (Dalton y Wattenberg, 1993: 193). Pero, además, detrás de todo modelo de voto se encuentra una discusión sobre el tipo de ciudadanía deseada y respecto de la relación que se establece entre representan- 
tes y representados en las democracias contemporáneas (Manin, Przeworski y Stokes, 1999). Por ello, el objetivo que en general ha servido de guía a todos los trabajos del comportamiento electoral es conocer cómo los votantes de las sociedades industriales avanzadas ejercen el complicado ejercicio del derecho de sufragio en las urnas para, a su vez, descifrar las claves de representación política en las democracias. Las respuestas a los interrogantes planteados han diferido mucho, pero en general puede decirse que ha habido dos grandes tendencias. Por un lado, está la solución promovida por los conductistas, que, en sus dos modelos, el de Columbia y el de Michigan, han tratado de buscar mecanismos sociales o psicológicos que reducen el mundo político de los ciudadanos cuando llega la hora de tomar decisiones políticas. Estos dos modelos han ido unidos a una cierta desconfianza en el ideal del ciudadano democrático. Por otro lado, se encuentra un tercer modelo, defendido por uno de los enfoques del posconductismo, que aboga por la existencia de una persona capaz de analizar su entorno más inmediato y de tomar decisiones consistentes con sus recursos, objetivos y creencias. Esta última visión está mucho más presente hoy día en los estudios de comportamiento electoral debido a la combinación del impacto del modelo racionalista, junto con las sucesivas revisiones de los modelos originales de Columbia y Michigan.

La aproximación sociológica al estudio del comportamiento político, o también conocida como la «escuela de Columbia», puso en marcha una tradición que ha sobrevivido hasta nuestros días a pesar de los continuos ataques y éxitos de otros enfoques. Hasta los años cuarenta del siglo pasado los instrumentos metodológicos sobre la base de datos electorales agregados fueron los dominantes entre los científicos sociales al introducirse en los estudios académicos electorales las entonces revolucionarias técnicas de encuesta (Lazarsfeld y otros, 1944). Este enfoque no era semejante a la aproximación sociológica tal y como la conocemos hoy. En aquel entonces - especialmente en los primeros pasos-, se trataban de estudios descriptivos sobre las características geográficas y sociológicas relacionadas con determinadas opciones electorales, aunque siempre bajo la presunción de que las condiciones sociales y del contexto geográfico, conjuntamente con la afiliación a determinados grupos o asociaciones, determinaban la acción política de los ciudadanos (Dennis, 1991: 57). En el contexto europeo los estudios desarrollaron su versión adaptada de este enfoque sociológico para el estudio del comportamiento electoral. En línea con la tradición macro histórico-sociológica del viejo continente, Lipset y Rokkan (1967) utilizaron el concepto de cleavage o conflicto político, hipótesis sobre el origen y evolución de los partidos y sistema de partidos políticos en Europa que se convierte en un punto de referencia obligado para cualquier investigador que desee desarrollar el análisis del voto desde una aproximación sociológica. La supuesta estabilidad de los cleavages planteaba problemas muy significativos 
en su formulación original (Ersson y Lane, 1982). Uno de ellos consistía en que Lipset y Rokkan jamás estudiaron en el nivel individual cómo se formaban las identidades sociales individuales dentro de los grupos sociales, y hubo que esperar a trabajos con datos de encuesta realizados posteriormente para demostrar la relación entre pertenencia a un grupo social y voto (Rose y Urwin, 1970; Heath y otros, 1985).

El enfoque psicosocial que se inicia en la Universidad de Michigan a finales de los años cuarenta y principios de los años cincuenta con los trabajos de Campbell y otros autores (1954 y 1960) constituye un nuevo impulso en el estudio del comportamiento electoral. Estos académicos encontraron una variable explicativa al observar la existencia de una cierta lealtad partidista. Aunque comparten la idea de que los grupos sociales son importantes, estos autores distinguen entre factores a largo plazo, integrados por un conjunto de actitudes de lealtad hacia los partidos que se desarrollan a temprana edad y que denominaron la identificación partidista; y factores a corto plazo, como los candidatos y los problemas o issues del momento, teniendo estos últimos un efecto muy secundario en el voto, por depender además del grado de identificación partidista de los electores. Los factores sociales son parte de los denominados de largo plazo, pero se ubican fuera del modelo explicativo del voto. Estas variables sociales aparecen como exógenas y solo tienen importancia al influir de forma indirecta sobre la identificación partidista o sobre algunos de los factores a corto plazo. De este modo, los individuos fueron recuperados en el análisis, y con ellos la psicología política. El objeto de análisis de los estudios electorales se centra en las actitudes y orientaciones hacia los partidos, los problemas y los candidatos, pero siempre otorgando un papel esencial a lo que se denominó la identificación partidista, que se constituye en el concepto central del denominado «modelo de Michigan». Estos estudios se constituyeron en la otra piedra angular de los estudios electorales y del conductismo, con el que compartían puntos de coincidencia. No es de extrañar que existiese una total coincidencia en ciertos elementos básicos entre este enfoque y el sociológico. Por ejemplo, el papel otorgado a las campanas electorales sigue siendo mínimo, lo mismo que el reducido papel otorgado a los medios de comunicación. Tampoco la ideología de los ciudadanos posee un lugar relevante en su modelo. Además, este modelo, al igual que el sociológico, considera que los ciudadanos individualmente considerados carecen de un conjunto de actitudes consistente o coherentemente organizado en torno a una ideología, adolecen del mínimo conocimiento de los issues de la campaña y, además, poseen un elevado desinterés por los asuntos políticos (Converse, 1964 y 1969; McClosky, 1964). También, al igual que ocurría con el modelo sociológico, se rechaza el ideal del ciudadano independiente y racional, ya que según la evidencia que presentan, son precisamente los ciudadanos independientes los que poseen menor grado de información política y menor consistencia ideo- 
lógica. Ambos modelos comparten la presencia de importantes presupuestos normativos, como conceder un papel casi secundario a la política y la creencia en la irracionalidad de las decisiones de los ciudadanos.

Era incuestionable que se avanzaba hacia el análisis de los vínculos psicológicos entre el electorado y los partidos, como ingrediente fundamental de la competencia partidista. La demostración empírica del debilitamiento de la identificación partidista comienza a detectarse tras un amplio crecimiento de votantes que se consideraban independientes, ciudadanos más sofisticados con mayor racionalidad en su comportamiento, que tenían un mayor nivel de información política y no se sentían anclados a los partidos (Rusk y Norpoth, 1982). Se inicia desde entonces un amplio y sugerente debate académico que encuentra en el cambio electoral en las democracias occidentales la principal variable a explicar (Dalton et al., 1984; Van Deth y Janssen, 1994). Si la existencia de fuertes niveles de identificación partidista había constituido un elemento de estabilidad política que atenuaba la posibilidad de cambios bruscos en el sistema de partidos, su debilitamiento se dejó notar en los sistemas de partidos. Paralelamente, la proliferación de encuestas contribuyó a incrementar la popularidad de estudios que encontraban en las divisiones sociales una variable explicativa de las orientaciones partidistas. La realidad política se operacionaliza a través del análisis de la influencia que tienen estas fracturas en los sistemas de partidos europeos y del análisis de su reflejo en las preferencias electorales. La falta de dinamismo del modelo Michigan que no contemplaba el desalineamiento de los votantes en los espacios ideológicos ni clarificaba las consecuencias sobre los sistemas de partidos no explicaba el cambio electoral que comienza a percibirse durante los años ochenta en las sociedades democráticas avanzadas (Dalton, Flanagan y Beck, 1984). La reducción del poder explicativo que habían tenido los indicadores sociales - la educación, la religión, la clase social, la edad, el género...- en las preferencias partidistas es un nuevo fenómeno que inunda a las sociedades (Franklin, Mackie y Valen, 1992; Evans, 1999). Este proceso había corrido paralelo al declive de la identificación partidista que no explicaba los cambios en las orientaciones electorales. Simultáneamente, la creciente volatilidad electoral modificó el patrón vigente desde los años veinte de los sistemas de partidos y se puso de relieve la inestabilidad causada por el debilitamiento de los lazos entre los clivajes y los partidos, demostrando con nuevos indicadores la descomposición que sufrían los sistemas de partidos.

La evolución del modelo de la escuela de Michigan se debió al claro declive de la identificación partidista con el consiguiente crecimiento de los independientes, una creciente volatilidad y cambios bruscos de opinión. Pero también a su incapacidad para explicar el cambio electoral más allá de las pequeñas oscilaciones que podían producirse. El modelo tal y como estaba formulado caracterizaba a los ciudadanos como estables 
(unmoved movers), es decir, como ciudadanos cuyas opiniones y actitudes fundamentales dependían de la identificación partidista, que, por definición, permanecía estable. De este modo, una de las mayores limitaciones del modelo consistía en su falta de dinamismo. Este dinamismo vino de la mano de trabajos amparados en la teoría del realineamiento político que apuntan a la posibilidad de que el entorno político, dependiendo de la edad del ciudadano, puede ayudar a conformar las identidades partidistas una vez transcurrida la etapa de la socialización inicial. Estas revisiones del modelo Michigan suponen reconocer la capacidad del electorado para discernir racionalmente, en determinados momentos críticos, la relevancia de distintos problemas sobre los que tienen que adoptar una postura. Este reconocimiento significa un punto de conexión con la literatura, hasta entonces marginal, promovida por Key (1966) sobre la teoría de las elecciones críticas y su defensa del ciudadano responsable. Sin embargo, estas revisiones siguen exhibiendo una carga normativa que se manifiesta en la deseabilidad de los momentos de realineamiento, que es cuando la identificación partidista es mayoritaria y fuerte. Los periodos de realineamiento son considerados como los de «normalidad», mientras que las otras etapas son caracterizadas por la excepcionalidad, inestabilidad y el peligro para la democracia. Esto último, en el fondo, significa tener una total desconfianza en la capacidad de los ciudadanos racionales de recoger información y de discernir la mejor opción posible sin contar con el «auxilio» de las identidades partidistas.

En la evolución de los presupuestos originales de la escuela de Michigan también ha tenido algo que ver el intento de aplicar el concepto de identificación partidista a la realidad europea. Pese a algunos intentos de evidenciar su aplicabilidad, lo cierto es que un número importante de académicos demostró su falta de adecuación porque en muchos países de Europa la identificación partidista mostraba al menos la misma inestabilidad que el voto (Thomassen, 1976; Van der Eijk y Niemöller, 1980). En su lugar se reemplaza este concepto por otro de carácter psicosocial como es la identificación con la izquierda-derecha. Estos conceptos funcionan como los referentes continuos e indispensables para la compresión y organización del mundo político y ayudan a efectuar juicios políticos y evaluar a los actores (Budge, Crewe y Fairlie, 1976; Sani y Montero, 1986; Fuchs y Klinglemann, 1989). La escala izquierda-derecha se convierte en el instrumento indispensable para abordar las preferencias partidistas y analizar la orientación del voto. Aunque la conceptualización de «izquierda»y «derecha» ha sido un asunto debatido en la literatura sobre comportamiento electoral, la comprensión de los términos es aceptable para la ciudadanía, identificándose con mayor facilidad si lo que se pone en cuestión es un partido o un líder político. Esta simplificación del universo político en polos opuestos permite ubicar a los objetos políticamente relevantes en un continuum y establecer relaciones de proximidad o distancia respecto a otros elementos políticos. Estas imágenes están arraiga- 
das en la sociedad y ayudan a generar una «identidad política» propia de los elementos del juego ideológico. A pesar de que las nociones de izquierda y derecha no son precisas ni estables, y tampoco son etiquetas rígidas, sino que su contenido varía con el tiempo, todo ello las dota de mayor riqueza conceptual y mantiene la esencia del desempeño de sus funciones organizativas y valorativas. De hecho, no tienen por qué gozar de precisión o de especificidad entre los electores, sino que deben ser adaptables a las situaciones políticas. El notable desarrollo experimentado en las sociedades industrializadas provocó que numerosos científicos señalaran las limitaciones que la escala izquierda-derecha manifestaba para estructurar el componente ideológico. Por otro lado, el cambio de valores reveló la multidimensionalidad de la ideología política a pesar de que estereotipos ligados a la ubicación seguían reflejando los vínculos partidistas existentes (Weisberg, 1980), e incluso los nuevos issues emergentes tampoco contribuían a la ubicación del electorado en la dimensión izquierda-derecha al no transformarse en preferencias partidistas (Van der Eijk y Niemöller, 1987). Fueron, en todo caso, los factores coyunturales los que se revelaron como elementos de peso en la operacionalización de la identificación ideológica (Miller, 1991). Durante los años setenta un creciente número de académicos detectó el importante crecimiento de ciudadanos que se declaraban independientes, es decir, sin identificación partidista. Esta evidencia condujo a algunos a alejarse del modelo formulado por Michigan y optaron por presentar unos ciudadanos más racionales e informados (Nie, Verba y Petrocik, 1979) que tendían crecientemente a depender menos de identidades partidistas y a poner más atención en los problemas de las campañas electorales y candidatos, es decir, en los elementos secundarios del modelo original, presentando una imagen de un ciudadano más sofisticado que la representada por el modelo de la escuela de Michigan.

Otra fuente de cambio en los estudios electorales proviene de los distintos enfoques que surgieron con posterioridad. Uno de ellos, el enfoque de la teoría racional, dio lugar a otro de los grandes modelos de los estudios electorales: el modelo económico o racionalista del comportamiento electoral. Este modelo se inicia con el trabajo de Downs (1957), que partía del supuesto de que los ciudadanos son «votantes racionales». La racionalidad debe buscarse en el contexto y en los medios y recursos. Es más, los votantes ordinarios son considerados capaces de efectuar análisis de costes y beneficios a la hora de tener que optar por un candidato o expresar su opinión sobre algún determinado problema que se presente en una elección. Mucho más cuando se afirma que lo racional es no estar informado, ya que el coste de la información siempre es más elevado que el beneficio obtenido con la misma. En este sentido defienden la analogía del mercado para representar la competición partidista y argumentan que, en el momento de la elección, los votantes se encuentran libres de presiones de los grupos a los que pertenecen, y, por tanto, toman decisiones individuales guiados por sus propios intereses. Este modelo 
postula que los electores son capaces de efectuar cálculos a la hora de votar considerando, por un lado, sus propias preferencias (utilidades) y, por el otro, la ponderación de las promesas de cada partido junto con su percepción de la labor gubernamental. Pero ¿cómo medir las actuaciones y promesas de cada partido en el gobierno? Cada votante posee unos intereses y posiciones sobre un conjunto de problemas que le afectan o preocupan. De este modo, la cuestión en una convocatoria electoral para el votante es evaluar lo que el gobierno se ha aproximado a sus objetivos y preferencias frente a lo que hubiera podido acercarse a ellas el partido que compite contra él. Los candidatos y los partidos, ordenados en el continuo de diversas posiciones y dimensiones, compiten para intentar convencer a los votantes de que ellos son los candidatos o partidos que consiguen los mayores beneficios, lo que significa que intentarán aproximarse al punto ideal del votante medio. Dadas unas determinadas condiciones, el equilibrio de esta situación es la convergencia en el centro del espectro ideológico de los partidos y de la mayoría de los votantes. Esta teoría trata, por tanto, de formalizar y calcular el resultado de la combinación del comportamiento del ciudadano y de los candidatos, o, para decirlo de otro modo, trata de observar cómo los votantes y los partidos interactúan durante las elecciones dentro de un espectro ideológico semejante y de un marco de referencia común para entender y evaluar la política.

Una de las direcciones en las que se ha desarrollado esta teoría racional de comportamiento electoral son los llamados modelos espaciales del voto, que constituyen un intento de desplegar y formalizar matemáticamente la dinámica de competición electoral entre partidos dentro del continuo de diferentes espacios de competición ideológica. Sin entrar en los problemas de toda esta literatura, parece incuestionable que se ha producido un cambio cualitativo en la dirección tomada por los estudios del comportamiento electoral desde la introducción de este modelo racional. El más aparente se observa en el creciente intento de convertir los modelos de Columbia y Michigan en no recursivos. Esto quiere decir que pretende demostrarse que los issues, la evaluación de los candidatos o la valoración de la labor desarrollada por un partido en el gobierno configuran las identidades partidistas (Feldman y Johnston, 2014). Es indudable que los estudios electorales presentan hoy a un votante mucho más sofisticado y racional, lo que ha abierto un campo infinito no solo en el debate teórico de la democracia, sino en un nuevo conjunto de grandes temas que se han constituido en el foco de atención de los estudios del comportamiento electoral (Kitschelt, 2000; Toubeau y Wagner, 2016; Oesch y Rennwald, 2018). El presente trabajo se enmarca en los modelos espaciales de proximidad del comportamiento electoral y trata de analizar los efectos que sobre aquel ejercen elementos de carácter contextual, cognitivo y evaluativo, presentes en el escenario político-electoral de las elecciones de 2015. 


\section{LA REDISTRIBUCIÓN DE LOS ANCLAJES IDEOLÓGICOS}

Numerosos síntomas que se advertían en el escenario político español, causados por factores de diversa índole, presagiaron los cambios que acaecieron en el sistema de partidos y definieron su nuevo formato tras las elecciones de 2015. Antes de esta fecha, incluso, desde mediados del primer decenio de los años 2000, los resultados de los sondeos de opinión mostraban ya variaciones significativas en la tendencia de apoyo y valoración al sistema democrático, advirtiéndose una acentuada pérdida de confianza en instituciones y en los actores políticos. Estos indicadores del sentimiento básico de los ciudadanos hacia su sistema político respondían a un fenómeno que afectaba a los sistemas democráticos de nuestro entorno y que indicaba una erosión de la calidad de la democracia representativa (Newton y Norris, 2000: 53). Sin ser un fenómeno propio de nuestro país, ya que en un buen número de sistemas democráticos eran patentes síntomas de distanciamiento respecto a las instituciones democráticas, cansancio o apatía hacia los procesos democráticos, lo cierto es que entre la opinión pública española se reflejaron ciertos indicios como baja participación electoral, escasa valoración del rendimiento de las instituciones políticas y de sus principales actores, y un incremento de votos de protesta hacia opciones minoritarias o antiestablishment en los procesos electorales (Dassonneville, 2018). La ciudadanía era crítica con el sistema democrático y comenzaba a reclamar un mayor nivel de influencia y participación en la gobernanza.

En el plano del comportamiento electoral, esta reacción se traduce en un declive manifiesto en la intención de voto a los dos partidos mayoritarios, debido, probablemente, a su mayor responsabilidad en la gestión de la crisis económica y sus consecuencias, pero, también, a su mayor protagonismo en la gobernanza de nuestro sistema político, que denotaba falta de transparencia, corrupción, selección de las élites por sus propios aparatos orgánicos o relaciones de enfrentamiento entre ambos partidos, comportamiento propio del ejercicio de política de adversarios bipartidista. Esto constituyó uno de los principales factores de desgaste y erosión del sistema partidista español, que facilitó un cambio sustancial de su estructura resultando en serias repercusiones sobre nuestra gobernabilidad.

Los datos de los sondeos de opinión ofrecen evidencias de que los sentimientos críticos hacia el funcionamiento del sistema democrático condujeron a un incremento de la cifra de españoles que se sentían insatisfechos con el funcionamiento de la democracia. Este hecho convivió con un progresivo deterioro de la intención de voto directo a PSOE y a PP y con el surgimiento en el escenario electoral de nuevas fuerzas políticas de origen diverso. Desde las elecciones de 2008, se aprecia una continuada debilidad en la intención de voto a los dos partidos mayoritarios y si bien su tendencia ofre- 
ce oscilaciones vinculadas a los ciclos electorales, desde 2012 se advierte un declive del que no se benefician otros partidos menores de ámbito nacional, como Izquierda Unida (IU) y, en aquel entonces, Unión Progreso y Democracia (UPyD). El punto de inflexión se sitúa en 2014 con la victoria de Podemos en las elecciones europeas y un año después con el incremento de 16 escaños que obtiene Ciudadanos en las elecciones autonómicas respecto a las elecciones de 2012. Estos dos acontecimientos ocurridos en el ámbito político subnacional trascienden el contexto de las elecciones generales de 2015. Ello facilitó que tanto Podemos como Ciudadanos presentaran en 2015 candidaturas en todas las circunscripciones, elevando el nivel de competitividad en todos los distritos electorales. Sin entrar a valorar los resultados, es bien conocido que ambos partidos obtuvieron unos niveles de representación política sin precedentes. Desde entonces, los españoles fueron conscientes de la fuerza y el protagonismo que adquirieron estos dos nuevos partidos. De hecho, la intención de voto que manifiestan los españoles en los sondeos de opinión hacia ambas formaciones, aunque con diversa intensidad, ha sido relevante. Sin lugar a dudas, también otros factores condujeron a este cambio en las orientaciones electorales, que se manifestaba por el debilitamiento en los anclajes que los españoles habían demostrado mantener con los partidos mayoritarios y que permitió que los niveles de volatilidad electoral alcanzaran cifras desconocidas hasta entonces.

\section{GRÁFICO 1}

Evolución de la intención de voto a partidos políticos (2008-2018)

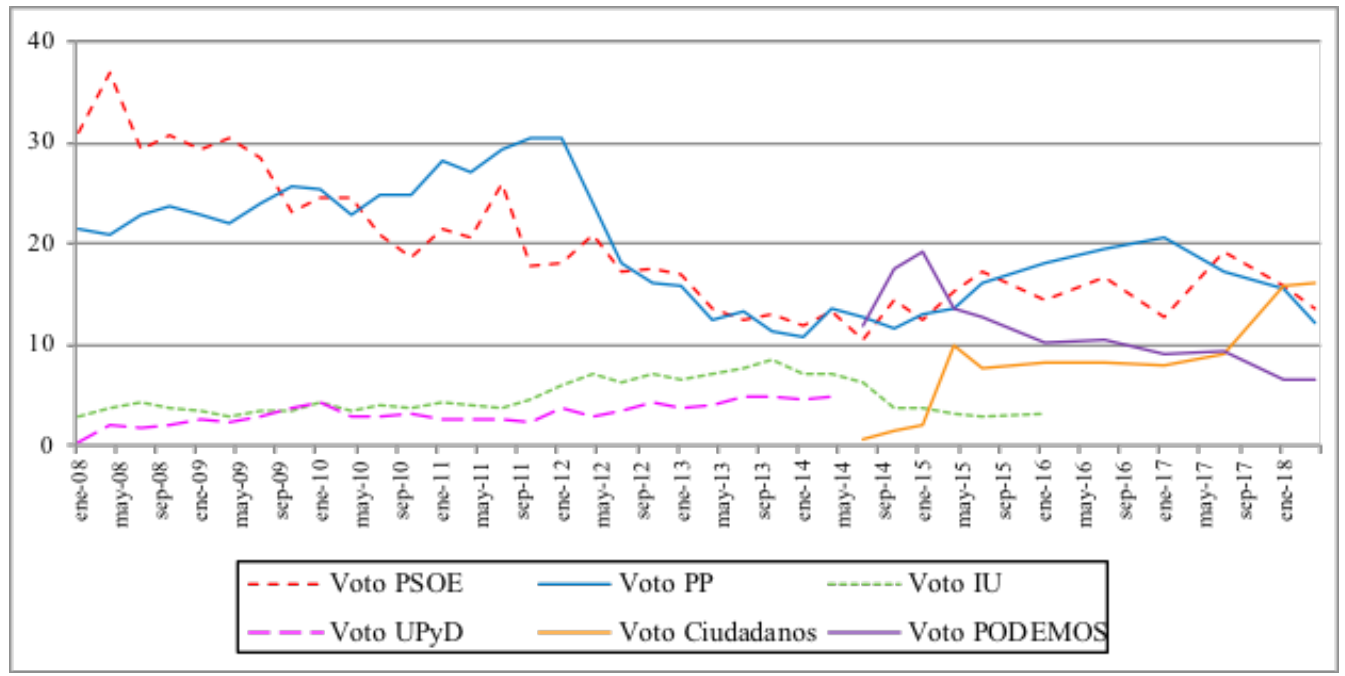

Fuente: elaboración propia a partir de datos del Centro de Investigaciones Sociológicas. 
Como consecuencia de la entrada de nuevos actores advertimos la reestructuración de la competencia partidista y el establecimiento de nuevos vínculos con los partidos, que sobre la base de la proximidad ideológica se traducen en apoyos electorales (Kitschelt y Wilkinson, 2009). Basados en el presupuesto de que la ideología es una variable del comportamiento electoral que facilita el atajo cognitivo a los ciudadanos, su medición a través de la escala izquierda-derecha permite explorar la dinámica de la distribución de los electores ofreciendo más información sobre los patrones de competencia partidista. Bajo este supuesto asumimos la equivalencia entre la proximidad ideológica-programática con un partido y el voto por este partido, combinando la lógica del modelo del partido responsable y del modelo de voto espacial. Aunque ello presupone que los ciudadanos seleccionen a los partidos tomando en consideración sus preferencias políticas o ideológicas, también exige que los partidos políticos se constituyan en alternativas políticas a través de propuestas ideológicas diferentes. La entrada de nuevos actores en el escenario supone una diversificación de las opciones que no siempre, desde el punto de vista del elector, significa cambios en la distribución ideológica. La autoubicación de los electores y la ubicación de los electores a los partidos en esta dimensión son dos aspectos diferentes. De hecho, en España, la entrada de nuevas formaciones políticas en la competición no parece alterar la distribución ideológica de los electores, sino que, más bien, diseña un nuevo reparto entre los partidos de los bloques ideológicos.

Efectivamente, si atendemos a la distribución de la autoubicación ideológica de los electores en España, es posible confirmar que no hay cambios importantes en los últimos dieciocho años (Medina, 2004: 42). La mayoría de los ciudadanos sigue situándose en las posiciones centrales de la escala de izquierda-derecha. Este indicador está dominado por el estatismo, y ello a pesar de que ha estado influido por mayorías gubernamentales de diferente signo político. Desde el año 2000, como se puede apreciar en el Gráfico 2, las variaciones apenas oscilan medio punto, desplazándose desde el 4,55 al 5,03. Este movimiento centrípeto representa a un electorado estable en sus orientaciones ideológicas, lo que ha condicionado la estrategia de los partidos, interesados en captar desde posiciones ideológicas diferentes a votantes de este centro ideológico para lograr la victoria en las elecciones. Así, entonces, el análisis de la relación entre ideología y voto no debería centrarse en el análisis de las orientaciones electorales de los individuos de cada posición de la escala, sino más bien a la inversa; esto es: será de mayor interés conocer en qué medida las posiciones de la escala se encuentran vinculadas a determinadas preferencias partidistas que las definen y les dan contenido. 


\section{GRÁFICO 2}

Evolución de la autoubicación media de los votantes (2000-2018)

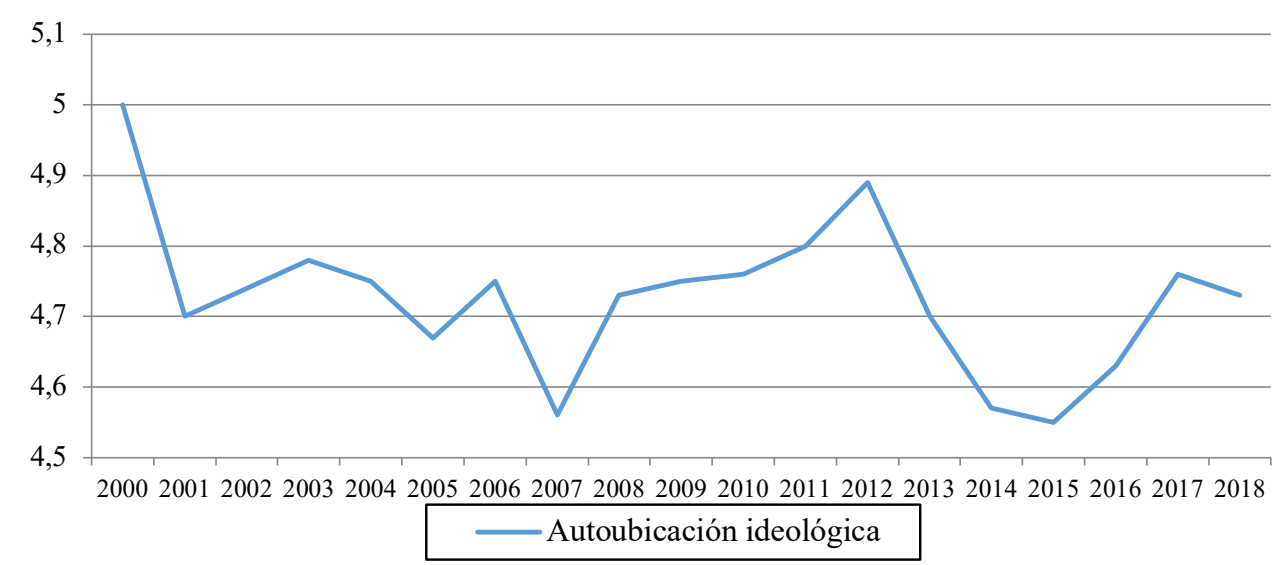

Fuente: elaboración propia a partir de datos del Centro de Investigaciones Sociológicas.

Desde esta nueva perspectiva, centrada en la distribución de los votantes de los partidos, las asignaciones de la ubicación ideológica denotan un rasgo dinámico. A pesar de los datos sobre la ubicación media de los ciudadanos antes señalada, es destacable que los votantes identifican claramente el espacio ideológico en el que se sitúan los partidos. Los individuos demuestran una singular capacidad cognitiva y evaluativa de la dinámica política en el contexto electoral español. De este modo ordenan la información política, lo que les facilita, además, desarrollar una proximidad ideológica con un partido. Desde esta primera dimensión, en España no ha sido complejo para los ciudadanos situar a los partidos políticos en el espacio ideológico. Hasta recientemente, la moderación venía caracterizando la ubicación de los partidos de ámbito nacional y la de sus votantes, pero la entrada en la competición de nuevos partidos políticos genera una reconfiguración de estos espacios ideológicos, influyendo en los índices de polarización. El nuevo reparto de espacios erosiona tanto a los partidos de la izquierda como a los de la derecha, y ello se debe a que cada uno de los dos nuevos partidos se sitúan respectivamente en estos dos espacios diferenciados. Este hecho coincide con la pérdida de fuerza del PSOE en la izquierda y el centro-izquierda y con el traslado del PP hacia las categorías de la derecha ideológica por la irrupción por el centro de un nuevo partido. Así, por un lado, Podemos se abre paso en el espacio de la izquierda, tanto en las posiciones más extremas - desplazando del lugar a IU— como en emplazamientos de la izquierda más moderada, 
como consecuencia del movimiento del PSOE hacia posiciones más centrales de la escala ideológica (Delgado-Fernández y Cazorla-Martín, 2017: 256). Por otro lado, el resquebrajamiento del centro permite la entrada de Ciudadanos en este espacio ideológico, a la vez que induce al desplazamiento del PP hacia la derecha. Como consecuencia de este reacomodo, la estrategia desarrollada por Podemos para incrementar las bases electorales y sumar votantes de la izquierda, pasa por desarrollar una táctica sumatoria con IU, lo que en 2016 le facilita la hegemonía en la izquierda ideológica. Este hecho tiene como efecto un contrapeso en la derecha, que reubica claramente a los votantes, particularmente a los del PP, en posiciones más extremas de la derecha ideológica. De hecho, si en 2008 el 59\% de los votantes del PP se situaba en posiciones de derecha (7-10), en 2015 esta cifra supera el 74\%. Advertimos, por tanto, que el equilibrio estático que caracterizaba el comportamiento electoral de los españoles se modifica una vez que nuevos partidos entran en la competición, generando un dinamismo que conduce a cambios, principalmente entre espacios ideológicos contiguos.

TABLA 1

Evolución de la autoubicación ideológica de los votantes de partidos (2008-2016)

\begin{tabular}{|c|c|c|c|c|c|c|}
\hline \multirow[b]{2}{*}{ Elección } & \multirow[b]{2}{*}{ Partido } & \multicolumn{5}{|c|}{ Autoubicación ideológica } \\
\hline & & $\begin{array}{c}\text { Izquierda } \\
(1-2)\end{array}$ & $(3-4)$ & $(5-6)$ & $(7-8)$ & $\begin{array}{c}\text { Derecha } \\
(9-10)\end{array}$ \\
\hline \multirow[t]{3}{*}{2008} & IU & 45,9 & 23,7 & 4,8 & 0,6 & 0,2 \\
\hline & PSOE & 6,9 & 38,4 & 27,1 & 3,7 & 1,1 \\
\hline & PP & 0,7 & 1,6 & 19,3 & 33,4 & 25,3 \\
\hline \multirow[t]{3}{*}{2011} & IU & 40,5 & 29,0 & 6,1 & 0,7 & 0,2 \\
\hline & PSOE & 9,5 & 39,8 & 27,4 & 4,3 & 0,8 \\
\hline & $\mathrm{PP}$ & 0,4 & 0,9 & 14,6 & 36,2 & 29,4 \\
\hline \multirow[t]{5}{*}{2015} & IU & 43,5 & 31,5 & 4,5 & 0,4 & 0,1 \\
\hline & Podemos & 50,3 & 16,0 & 6,6 & 1,3 & 0,4 \\
\hline & PSOE & 7,9 & 39,3 & 29,9 & 6,6 & 1,6 \\
\hline & Ciudadanos & 2,1 & 5,5 & 31,2 & 24,7 & 8,5 \\
\hline & $\mathrm{PP}$ & 0,4 & 0,6 & 9,4 & 36,3 & 38,2 \\
\hline \multirow[t]{4}{*}{2016} & Unidos Podemos & 52,8 & 21,3 & 4,2 & 1,0 & 0,4 \\
\hline & PSOE & 6,6 & 38,5 & 26,1 & 8,2 & 2,5 \\
\hline & Ciudadanos & 1,3 & 3,9 & 35,7 & 25,1 & 12,3 \\
\hline & $\mathrm{PP}$ & 0,9 & 0,6 & 9,5 & 34,3 & 38,5 \\
\hline
\end{tabular}

Fuente: elaboración propia a partir de datos del Centro de Investigaciones Sociológicas. 
En realidad, el patrón de la evolución del posicionamiento sugiere la importancia del componente partidista en la escala ideológica. No podemos afirmar que los anclajes ideológicos se hayan debilitado, sino que se ha producido un reparto de votantes entre más partidos que entran en competencia por el voto y, por tanto, genera un nuevo realineamiento en el que la ideología sigue desempeñando un papel predominante para estructurar las preferencias y desarrollar vínculos partidistas. Esta lógica de proximidad espacial se puede abordar además a través de las transferencias de voto entre dos elecciones sucesivas.

En 2015, los cambios más importantes pivotan alrededor de la pérdida de votos del PP y del PSOE. El porcentaje de voto que conserva cada partido respecto de 2011 muestra que la tasa de fidelidad fue reducida, siendo más acusada en el caso del PSOE. Ambos partidos pierden votantes en favor de Podemos y de Ciudadanos en magnitudes diferentes. La capacidad de retención de votantes se vio limitada por la presencia de estas nuevas formaciones políticas cuya proximidad ideológica facilitó la fuga. También fue significativa la proporción de electores que votaron en blanco en 2011 y optaron por apoyar a Ciudadanos. La mayor retención de voto se produjo en el PP, fenómeno, por otra parte, ya conocido por los analistas (Sánchez-Cuenca, 2003). El 64\% de sus votantes vuelve a votarlo en 2015 y, por otro lado, este partido capta a un 4,6\% de votantes socialistas. No sorprende, sin embargo, que un 18,3 de votantes populares modificara su voto y apoyara a Ciudadanos. Como tampoco resulta extraño que el abandono de votantes socialistas sea captado por las dos nuevas formaciones políticas, dada la proximidad ideológica a ambos lados de la escala. No obstante, la mayor dispersión del voto se localiza en UPyD y en IU, en las dos formaciones más minoritarias. Dos de cada cuatro votantes de IU transfiere su voto a Podemos. Esta cifra revela la magnitud de la volatilidad intrabloques que ha caracterizado a las elecciones de 2015, aspecto éste alimentado también por la significativa pérdida de votos de UPyD en estas elecciones generales.

TABLA 2

Transferencia de voto entre elecciones generales de 2011 y 2015

\begin{tabular}{clrrrrr}
\hline & \multicolumn{5}{c}{ Recuerdo de voto elecciones generales 2011 } \\
\cline { 2 - 7 } Recuerdo & & PSOE & PP & IU & UPyD & En blanco \\
\cline { 2 - 7 } de voto en & PSOE & 53,2 & 4,6 & 5,5 & 5,4 & 4,0 \\
elecciones & PP & 3,5 & 64,2 & 0,7 & 4,5 & 9,0 \\
generales & IU & 2,9 & 0,6 & 25,3 & 3,6 & 1,0 \\
2015 & Podemos & 20,2 & 3,2 & 46,3 & 19,6 & 15,0 \\
& Ciudadanos & 7,8 & 18,3 & 4,1 & 55,4 & 19,0 \\
& Voto blanco & 1,0 & 0,1 & 0,2 & 1,8 & 19,0 \\
\hline
\end{tabular}

Fuente: elaboración propia a partir de datos del estudio postelectoral del Centro de Investigaciones Sociológicas. 
Estos datos constatan que la identificación espacial canaliza las preferencias del votante hacia un determinado partido al considerarlo próximo al espacio ideológico al que el propio votante siente pertenecer. Este comportamiento electoral se guía por la lógica de la menor distancia. Aunque existen factores que pueden obligar al elector a modificar su opción partidista y escoger a otro partido ideológicamente más alejado, la lógica de la proximidad espacial parece ofrecer una explicación relevante sobre la estructuración de las preferencias partidistas en el contexto español. Desde el plano teórico, los sistemas de valores y creencias de las personas son fundamentalmente de carácter emotivo y se vinculan con el afecto y los lazos desarrollados hacia los actores políticos. El apoyo partidista se relaciona por tanto desde esta perspectiva con la ubicación ideológica de los partidos. Al analizar el grado de proximidad que manifiestan los ciudadanos respecto de los partidos de ámbito nacional en función de las posiciones en la escala de ideología se aprecia que la competencia por los espacios centrales de la escala se dirime entre el PSOE y Ciudadanos, siendo un lugar más proclive a situarse aquellos ciudadanos que se sienten más cercanos al PSOE: un $25 \%$ de españoles que se sitúan en la posición 5 de la escala se sienten cercanos a este partido. Este razonamiento cuestiona la fundamentación de que la victoria en las recientes elecciones legislativas de 2015 haya estado vinculada la captación de un mayor número de electores del centro ideológico. Es decir, la victoria de los partidos políticos no solo se produce por la conquista del voto del centro de uno de los partidos, sino por el movimiento entre las posiciones del centro, centro-izquierda y centro-derecha que reflejan un cambio de las propias preferencias partidistas de los votantes. El esquema izquierda-derecha y los contenidos que se asocian a ella han estructurado, entre otros elementos, la comprensión del espacio político influyendo sobre el voto. Además, los españoles no parecen tener dificultades a la hora de expresar una identificación ideológica que vaya más allá de una ubicación en una escala numérica. El espacio ideológico que hemos definido como izquierda se vincula a la ideología socialista y progresista. Así se define el $41 \%$ de los entrevistados y el $43,7 \%$ de los que se sitúan en el centro-izquierda. El centro del espacio ideológico es compartido por varias ideologías: un $16,7 \%$ se siente Liberal y un $15 \%$ Conservador. Pero también un $10 \%$ de los ciudadanos comparte, respectivamente, otros sentimientos ideológicamente más distantes y se sienten Socialistas, Progresistas o Socialdemócratas. La indefinición ideológica en el centro de la escala refleja una gran imprecisión, por lo que este espacio se convierte en un lugar heterogéneo, un espacio que denota disponibilidad para captar a votantes con diversas orientaciones ideológicas. En síntesis, los españoles situados en el centro ideológico están más abiertos a ofertas electorales con rasgos ideológicos diversos. Una mayor precisión de los contornos ideológicos se advierte en los espacios de la derecha. Más de la mitad de los ciudadanos son conservado- 
res, apreciándose algún grupo que se siente demócrata-cristiano. Respecto de otras ideologías más minoritarias, los electores de izquierda son más proclives a identificarse con ellas. El 8,6\% de los que se sitúan en posiciones de extrema izquierda se declara nacionalista y un 6,7\%, ecologista. Apenas figuran estas clasificaciones en los espacios de la derecha.

TABLA 3

Definición ideológica de los electores según autoubicación ideológica

\begin{tabular}{lccccc}
\hline \multirow{1}{*}{ Ideología } & \multicolumn{5}{c}{ Autoubicación ideológica* } \\
\cline { 2 - 6 } & $\begin{array}{c}\text { Izquierda } \\
(\mathbf{1 - 2 )}\end{array}$ & $\begin{array}{c}\text { Centro-izquierda } \\
\mathbf{( 3 - 4 )}\end{array}$ & $\begin{array}{c}\text { Centro } \\
\mathbf{( 5 - 6 )}\end{array}$ & $\begin{array}{c}\text { Centro-derecha } \\
\mathbf{( 7 - 8 )}\end{array}$ & $\begin{array}{c}\text { Derecha } \\
\mathbf{( 9 - 1 0 )}\end{array}$ \\
\hline Conservador & 1,6 & 2,9 & 14,7 & $\mathbf{4 1 , 0}$ & $\mathbf{5 2 , 7}$ \\
Demócrata-cristiano & 0,5 & 1,4 & 6,4 & 15,9 & 12,8 \\
Liberal & 9,0 & 9,8 & $\mathbf{1 6 , 7}$ & 12,0 & 10,1 \\
Progresista & 16,8 & 15,1 & 9,6 & 5,3 & 3,7 \\
Socialdemócrata & 6,2 & 11,8 & 9,4 & 3,6 & 0,5 \\
Socialista & $\mathbf{2 4 , 4}$ & $\mathbf{2 8 , 6}$ & 9,4 & 0,9 & 1,1 \\
Comunista & 10,3 & 3,5 & 0,7 & 0,4 & 0,0 \\
Nacionalista & 8,6 & 4,7 & 3,9 & 1,4 & 0,5 \\
Feminista & 4,1 & 2,0 & 1,0 & 0,6 & 0,5 \\
Ecologista & 6,7 & 4,2 & 2,9 & 0,6 & 1,6 \\
\hline
\end{tabular}

* Los porcentajes son de columna. No suman 100 porque no se han considerado otras respuestas incluidas en la pregunta.

Fuente: elaboración propia a partir de datos del estudio postelectoral del Centro de Investigaciones Sociológicas.

\section{DELIMITANDO LOS FACTORES ORIENTADORES DEL VOTO EN LAS ELECCIONES GENERALES DE 2015}

Los resultados de las elecciones generales de 2015 han roto con el planteamiento comúnmente aceptado en España de que quien gana el centro ideológico gana las elecciones. Por varias razones. Una, porque el centro ideológico se ha desdibujado y ha sido captado por diversas fuerzas políticas a través de mensajes diferenciados. La estrategia desarrollada por los partidos para activar los vínculos con el electorado se basó en una oferta programática e ideológica diferenciada para que fuese reconocida por el votante. Los nuevos partidos trataron de lanzar mensajes con contenidos diferentes a los de los partidos tradicionales de quienes querían distanciarse, aun a sabien- 
das de que ello podría tener consecuencias en relación con la captación del votante centrista. La segunda razón, consecuencia de la anterior, es que la oferta partidista fue mayor y fragmentó la distribución tradicional de los apoyos electorales de los partidos. La polarización generada ha conformado una distribución de los partidos a lo largo del espectro ideológico en el que ha dominado principalmente la técnica de captar votos de individuos próximos ideológicamente al espacio en el que se ubican los partidos, lo que parece activar, en esta ocasión, el voto ideológico. Y ello, a pesar de que Podemos renunciara explícitamente a tomar una posición clara en el eje ideológico durante la campaña electoral. Para concentrar el interés de los votantes descontentos con el sistema, críticos con la labor del Gobierno, Podemos diseñó una nueva identidad en la que predominaron los aspectos transversales frente a los tradicionales. Ciudadanos optó de una forma más moderada por desarrollar estrategias en las que se distanciase ideológicamente de su partido competidor más cercano, el PP, escogiendo concentrar la atención en factores que favorecieran no solo la captación del electorado ideológicamente próximo a su partido, sino destacando también otros valores como el recambio generacional o la regeneración democrática. Los nuevos partidos tenían en contra (o en favor) que la experiencia/madurez de los partidos tradicionales dificultaría el establecimiento de nuevos anclajes sobre la base de elementos tradicionales de comportamiento electoral, pero a su vez conocían que la estructuración de las preferencias partidistas se nutre de atajos cognitivos donde la ideología desempeña un papel indiscutible.

Los electores han estado expuestos a nuevos contenidos de carácter político que han podido incidir en la formación de sus creencias políticas, aun a pesar de que han existido vínculos ideológicos. Pero también sostenemos que factores contextuales de corto plazo han determinado la orientación del comportamiento electoral. Lógicamente, el escenario en el que se convocan las elecciones de 2015 viene precedido por consultas electorales en otros niveles territoriales que permitieron a los ciudadanos optar por otras formaciones políticas diferentes a la que dominaban en la escena nacional. Algún «voto de castigo» que se gesta en un ambiente de descontento e insatisfacción con el sistema político y con sus actores. Si visualizamos el Gráfico 3, advertimos que los ciudadanos más críticos con el funcionamiento del sistema son aquellos que se sitúan en posiciones de la izquierda en la escala; y, contrariamente a lo señalado en otras etapas de la nuestra democracia, los electores que se ubican en la derecha son los que se sienten más satisfechos con el sistema democrático. La tendencia de la gráfica muestra, por tanto, la correlación positiva entre ideología y satisfacción con el funcionamiento de la democracia, caldo de cultivo sin precedentes para permitir la irrupción de nuevas formaciones políticas. 


\section{GRÁFICO 3}

Grado de satisfacción con la democracia según autoubicación ideológica

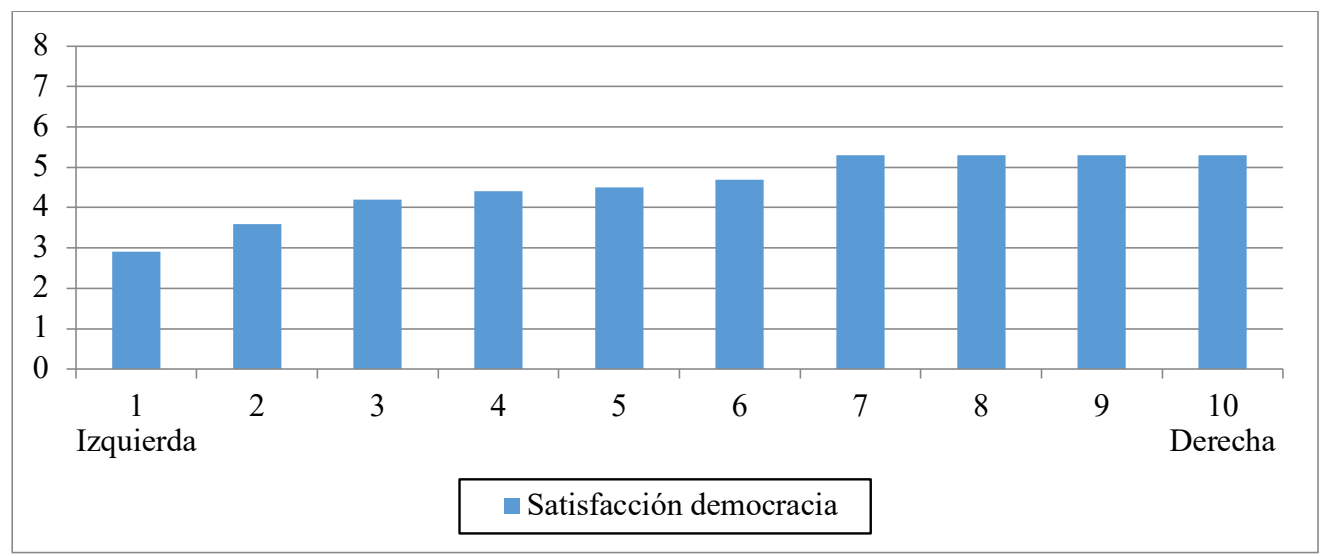

Fuente: elaboración propia a partir del estudio postelectoral 2015 del Centro de Investigaciones Sociológicas.

El malestar democrático entre los electores de la izquierda también se aprecia en su valoración respecto de los indicadores de confianza política y de expectativas de mejora política. En términos generales, los ciudadanos muestran un sentimiento de desconfianza, de incapacidad para influir en el sistema político y de insatisfacción en la respuesta que el sistema puede ofrecer ante sus demandas. Los españoles reclaman instituciones eficaces - ya que son críticos respecto de las valoraciones que de ellas realizan - y reivindican la importancia de estar bien gobernados. Los bajos niveles de confianza institucional y en especial desconfianza respecto a los partidos y a los políticos es una muestra de esta actitud crítica que se transforma en «problema» (Torcal, 2010). Y ello es producto de una imagen vinculada a la actividad que desarrollan los actores políticos, en la que predominan intereses de carácter personal-partidista, frente al interés general que reclaman los ciudadanos. El motivo por el cual los electores han votado en las elecciones generales de 2015 a sus partidos es diverso. El 53,1\% de los votantes de Podemos destacan que es el que mejor representa sus ideas, y de igual manera contesta el 40,3 \% de los votantes de Ciudadanos. Sin embargo, el 37,4\% de los votantes del PSOE manifiesta que su voto a este partido ha estado vinculado a la lealtad partidista, es decir, siempre vota al mismo partido; y el 33,8\% de los votantes del PP destaca la capacitación de este partido para gobernar. Como se puede apreciar, las valoraciones son diversas, pero permiten confirmar que elementos como el liderazgo o el voto útil no son señalados por los votantes de ningún partido como factores decisorios de la opción partidista en las elecciones generales de 2015. 
Estas actitudes ciudadanas relacionadas con la eficacia externa del sistema contienen un componente partidista que se vincula con la valoración del desempeño del gobierno, con su capacidad de respuesta a las demandas ciudadanas. Si analizamos el caso español, observamos que las percepciones sobre la valoración de los diferentes gobiernos han fluctuado en el tiempo (Montero et al., 1998: 20) a la vez que se aprecia una tendencia similar a aquel si se valora la actuación de los grupos de la oposición. En un momento inicial parte del éxito de la transición a la democracia revertió sobre el gobierno de UCD y se extendió a los gobiernos de Felipe González. No fue hasta principios de los años noventa cuando las valoraciones críticas respecto del ejecutivo se acentuaron. De hecho, hasta las elecciones de 1989 no existieron indicios de una alternancia política viable en la cámara baja, y la etapa de mayoría absoluta del PSOE impulsó, durante tres legislaturas, una dinámica parlamentaria que tuvo como consecuencia el inmovilismo político, el agotamiento de la función programática del gobierno a la vez que estuvo jalonada por diferentes casos de corrupción política. Los electores no fueron ajenos a este contexto y en las elecciones de 1993 el PSOE perdió la mayoría absoluta y, por tanto, su posición de hegemonía respecto al resto de los partidos con representación parlamentaria. Los resultados de aquellas elecciones legislativas supusieron un cambio en el rumbo político y dieron inicio a un modelo de sistema pluripartidista limitado no polarizado, con mayores componentes de moderación, en el que se potenció el papel de los grupos de la oposición en la cámara baja. En 1996, en un marco de devaluaciones de la peseta, de fuerte tasa de paro, de creciente desgaste socialista, de aparición de nuevos casos de financiación ilegal y de corrupción, de graves problemas internos en el PSOE, el clima de descontento político se había extendido ya entre los ciudadanos. Esta insatisfacción política se percibió claramente a través de las valoraciones ciudadanas del binomio gobierno-oposición, que han evolucionado de forma paralela a las valoraciones de la situación económica y política. La recuperación económica que se logra durante finales de los años noventa mejoraron las evaluaciones de la labor del gobierno reduciendo las de la oposición. De hecho, los datos reflejan que existe una covariación casi perfecta entre la valoración de la situación económica y la valoración de las condiciones políticas, y que ambos factores corrían parejos a las cambiantes circunstancias de rendimiento del gobierno y de la oposición. No obstante, es en el periodo 20102012 cuando la ciudadanía es más crítica con el gobierno, preanuncio del cambio acontecido en 2011, y tras lo cual repuntó los niveles de confianza política e institucional, que volvieron a descender, destacando si cabe, en mayor medida, el declive de la valoración de la situación política, rasgo idiosincrático de la valoración ciudadana actual.

Si analizamos el indicador de valoración de la situación política y de la situación económica en relación a la dimensión izquierda-derecha en el contexto de las elecciones de 2015, observamos una tendencia similar a la señalada para valorar el funcionamiento 
de la democracia. Las mayores críticas proceden de los votantes de la izquierda que mantienen una actitud crítica hacia el rendimiento de la política y la evolución de la economía. Existe una pauta clara en el aumento de las percepciones negativas del estado de la economía y del estado de la política y la ubicación ideológica. El Gráfico 4 sugiere que, efectivamente, las valoraciones de los ciudadanos sobre el estado de la economía y el estado de la política están relacionadas con la ideología, puesto que el mayor pesimismo de los electores se traslada hacia la izquierda de la escala. Las diferencias en la tendencia de estos dos indicadores siguen pautas similares: los ciudadanos de izquierda valoran más negativamente la situación económica que la valoración de la situación política. Por tanto, los ciudadanos situados en la derecha ideológica valoran más negativamente la política y consideran más positivamente la economía. El efecto del voto económico, por una parte, y el voto político-contextual, por otra, se relacionan con otros elementos que orientan el comportamiento de los electores. La crítica a la gestión gubernamental se correlaciona con la ideología y, de forma más acentuada que en el caso de los dos indicadores anteriores. Los elementos que valoran los ciudadanos de la gestión gubernamental son una combinación de pesimismo sobre la marcha de la economía y respecto de la situación política, por un lado, y por otro, la atribución de responsabilidad de esta situación al gobierno. Y en este proceso, la ideología resulta ser una herramienta útil para procesar la información y emitir un juicio valorativo sobre estos aspectos (Fiorina, 1981: 200).

\section{GRÁFICO 4}

Distribución de la valoración de la economía, la política y la gestión gubernamental según autoubicación ideológica

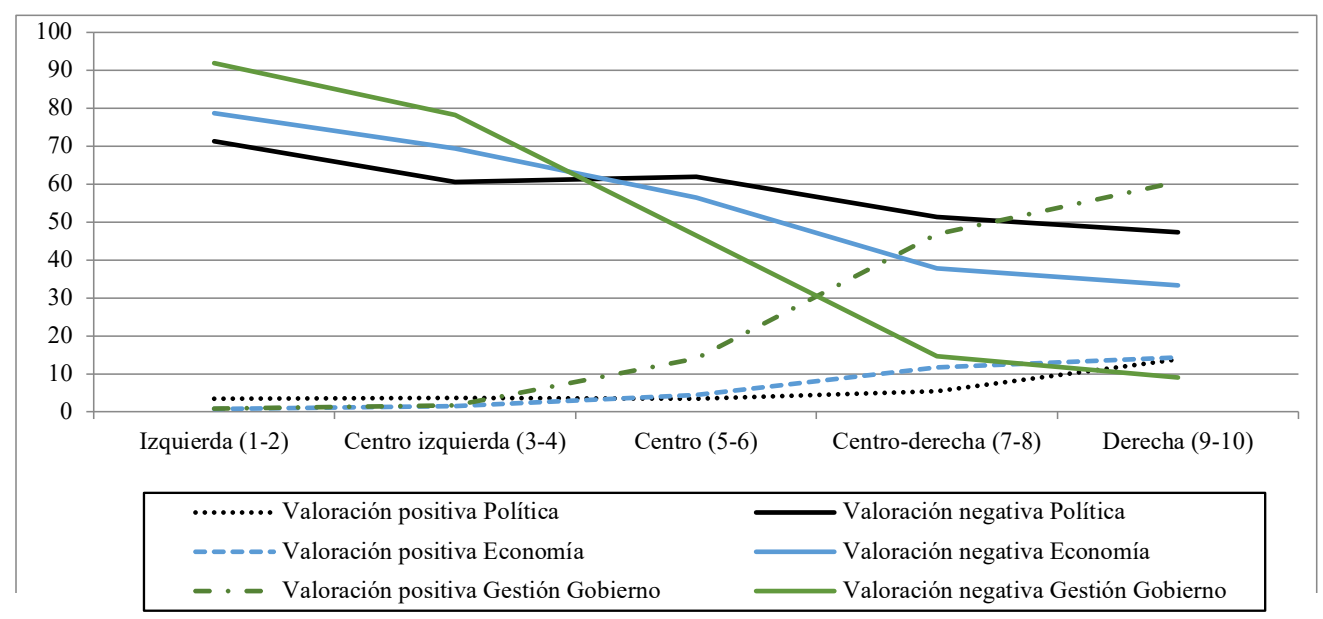

Fuente: elaboración propia a partir del estudio postelectoral 2015 del Centro de Investigaciones Sociológicas 
Este desapego institucional, germen de un descontento político más generalizado, se muestra en relación a la implicación psicológica de los ciudadanos en la política, sus actitudes afectivas y su percepción de proximidad a la dimensión interna de la eficacia política. Basta analizar si los ciudadanos, independientemente de la imagen que tengan de las instituciones y de los políticos, sienten una cierta curiosidad hacia los asuntos políticos y si se perciben a sí mismos como capaces de entender y de participar en el proceso político. Un indicador para delimitar este nivel de desafección política es la implicación psicológica del ciudadano en política que podemos medir a través de las respuestas que ofrecen en relación al interés por la política y la frecuencia con la que discuten de política en el entorno más cercano. Se trata de dos elementos que componen el nivel de implicación personal en la política y que son las actitudes que mayor influencia positiva generan sobre la participación política. Aunque los niveles varían en función del nivel político, es comúnmente aceptado que la política nacional es la que mayor interés despierta. En España, este indicador no ha sufrido grandes oscilaciones y, hasta 2012, el $20 \%$ de los españoles declaraba tener interés (mucho y bastante) en la política. Desde entonces, el interés por la política ha ido creciendo progresivamente, alcanzando en 2014 un 39,5\%, y en 2015 un 41,1\%. De forma similar, habitualmente un $25 \%$ de

\section{GRÁFICO 5}

Distribución del interés por la política según autoubicación ideológica

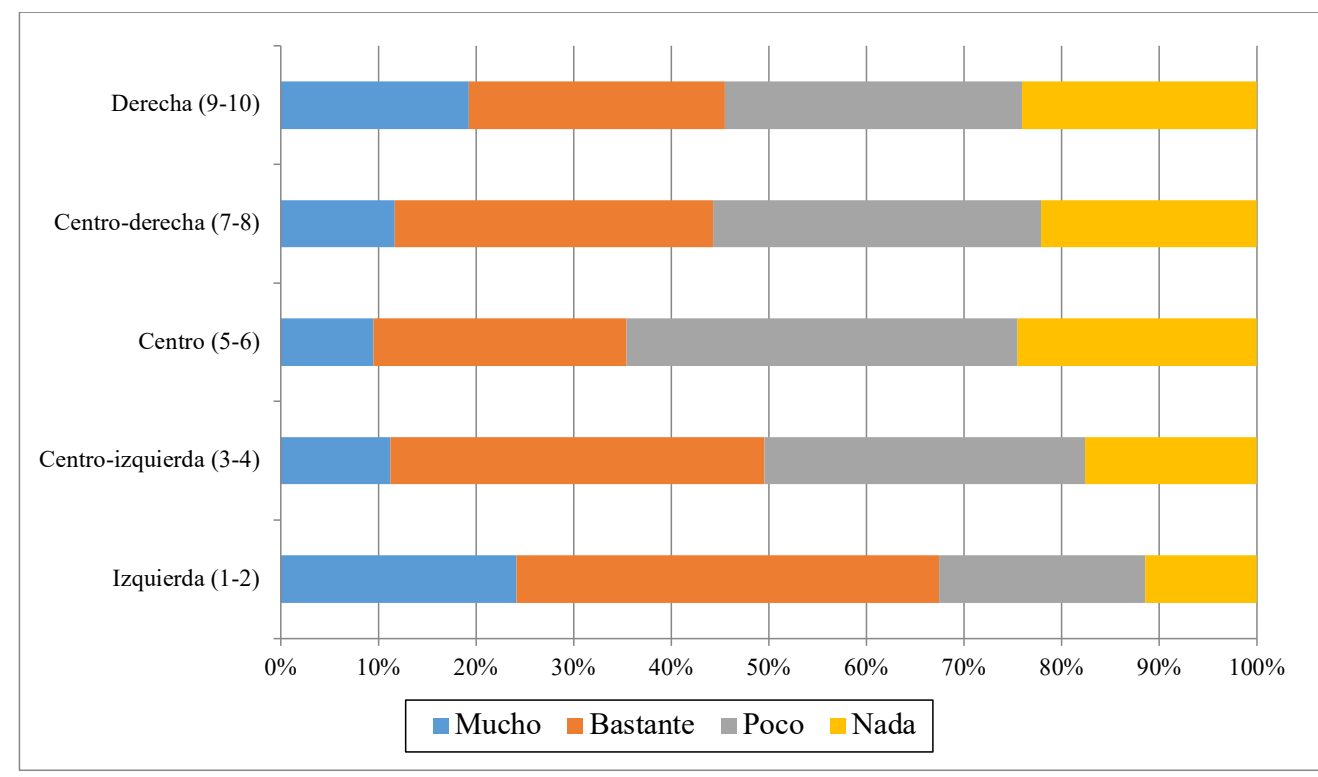

Fuente: elaboración propia a partir del estudio postelectoral 2015 del Centro de Investigaciones Sociológicas. 
los españoles discute de política en el entorno más cercano, valor que alcanzaba en 2013 tan solo un $10 \%$. Los resultados de ambos indicadores permiten confirmar que el nivel de desafección, atendiendo a estos datos, está mermando. Pero, por otra parte, ¿cómo se distribuyen las actitudes hacia todos estos asuntos de naturaleza política dentro del esquema izquierda-derecha? Los ciudadanos de centro son los que menor interés por la política muestran frente a los de centro-izquierda e izquierda, que se caracterizan por tener unas actitudes de mayor interés por la política.

Dado que el comportamiento electoral no es determinista, es conveniente ampliar el horizonte explicativo y ampliar los resultados de los análisis bivariados realizados hasta ahora con propuestas de modelos multivariables con mayor potencial explicativo. Para ello, planteamos a continuación un análisis que controla simultáneamente varias de las dimensiones analizadas del comportamiento de los electores que están vinculadas con el esquema izquierda-derecha. La variable dependiente es el voto declarado en las elecciones de 2015, y, dado su carácter, recurrimos a una ecuación de regresión logística multinomial que nos permite predecir la probabilidad de que un elector tenga un determinado comportamiento en función de las variables explicativas seleccionadas. En la medida en que la pérdida de votos del partido en el gobierno ha sido significativa, consideramos interesante recoger los coeficientes correspondientes a la comparación entre el PP y los partidos de ámbito nacional que han captado a estos votantes populares, esto es PSOE, Ciudadanos y Podemos. Por tanto, la variable dependiente es el recuerdo de voto de los electores en diciembre de 2015, recodificada en las cuatro categorías de partidos señaladas.

Las variables relevantes para explicar este comportamiento las hemos agrupado en aquellas que están vinculadas con las valoraciones del contexto electoral y la oferta de los partidos políticos, esto es, la valoración de la situación política y de la situación económica, y la valoración de la gestión gubernamental, y otro grupo que toma en consideración las actitudes hacia el sistema político, operacionalizadas a través del nivel de satisfacción con la democracia, y la ideología — ambas medidas en una escala de 10 puntos-, el interés por la política, la cercanía y el grado de confianza en los partidos políticos, con categorías que representan a los valores mucho-bastante-poco-nada. Además de estas variables explicativas en el modelo se introducen varios controles relativos a las características sociodemográficas de los electores: el género, su edad medida en años cumplidos, el nivel de religiosidad medida a partir de la frecuencia de la práctica religiosa, y que oscila entre las categorías 1, que representa casi nunca, hasta 5, que representa varias veces por semana. El nivel de estudios, variable ordinal que toma cinco valores: sin estudios, educación primaria, educación secundaria, estudios de FP, estudios universitarios medios y estudios universitarios superiores. Y también se incluye la clase social, medida en una escala de 10 puntos. Queremos comprobar qué aspectos han 
tenido más influencia a la hora de decidir el voto, si los contextuales o si existe un efecto generado por las actitudes de largo plazo que los ciudadanos han desarrollado en relación al sistema y sus actores políticos.

Los resultados de la estimación de estos modelos se presentan en la Tabla 4. Con estos modelos trata de mostrarse dos cuestiones. Primero, el peso relativo de las variables coyunturales y de las actitudes en la orientación del voto. En este sentido, la expectativa es que las actitudes tengan una importancia mayor y que la ideología desempeñe un papel destacado a la hora de definir el apoyo a los partidos y, por tanto, se espera que el efecto de otras variables sobre el comportamiento electoral sea menor. Por el otro, y este sería el segundo aspecto a contrastar, dado que la ideología es una variable de carácter político, y en la literatura reciente se ha prestado atención a la influencia de elementos de carácter económico sobre la orientación del voto, se pretende calibrar la influencia y la valoración de la situación económica sobre la orientación del voto en estas elecciones generales. Sostenemos que la relevancia otorgada a valoraciones de carácter político o la propia valoración de la gestión gubernamental que realizan los ciudadanos tienen un mayor efecto estructurador de las preferencias electorales en contextos de elevada competencia electoral.

El modelo estimado muestra que las variables sociodemográficas son insignificantes desde el punto de vista estadístico para todos los partidos analizados, con excepción de la religiosidad y el nivel de estudios, en el caso de Ciudadanos y Podemos, lo cual, por otro lado, es coherente dado el número tan elevado de factores incluidos en el modelo. La influencia de la ideología es, en cambio, significativa y tiene efectos en la dirección esperada en el contraste entre los tres partidos de referencia. De igual forma la confianza respecto a los partidos políticos tiene efectos desiguales sobre el voto en función de los partidos que se consideren, siendo solo significativa esta variable para orientar el voto de Podemos. La valoración de la situación económica no tiene un efecto estadísticamente significativo, siendo relevante la valoración de la situación política y la gestión gubernamental en el caso del contraste de voto entre PP y Podemos.

Los resultados demuestran la existencia de dinámicas de adaptación de las identificaciones ideológicas de los electores en función de estrategias y movimientos de los partidos sobre el esquema izquierda-derecha. Los electores desarrollan identidades políticas que se configuran a través de su aprendizaje político directo con el propio sistema (Fiorina 1977). Las personas se sienten de izquierdas, de centro o de derechas porque procesan las influencias que reciben del entorno político, así como valoran las actuaciones de los partidos que compiten en el escenario político. Estas dinámicas de carácter cognitivo-evaluativo conducen a la (re)construcción racional de las identificaciones ideológicas de los electores (Torcal y Medina 2002) y originan el desarrollo de procesos de realineamiento ideológicos que conducen a cambios electorales. 
TABLA 4

Ecuaciones de predicción del voto al partido en el gobierno (PP) frente a otras opciones

\begin{tabular}{|c|c|c|c|}
\hline & Ciudadanos & PSOE & Podemos \\
\hline \multirow[t]{2}{*}{ Género } & $0,219 *$ & 0,077 & $-0,333$ \\
\hline & $(0.092)$ & $(0.156)$ & $(0.403)$ \\
\hline \multirow[t]{2}{*}{ Edad } & $0.012 *$ & $-0,110$ & $-0,049$ \\
\hline & $(0.001)$ & $(0.006)$ & $(0.006)$ \\
\hline \multirow[t]{2}{*}{ Nivel estudios } & $0.432 * * *$ & 0,439 & $0.567 * * *$ \\
\hline & $(0.087)$ & $(0)$. & $(0.527)$ \\
\hline \multirow{2}{*}{ Clase social } & 0,879 & 0,152 & $-0,605$ \\
\hline & $(0.234)$ & $(0.172)$ & $(0.171)^{* *}$ \\
\hline \multirow[t]{2}{*}{ Religiosidad } & $0.354 * *$ & $-0,152$ & $-0,136$ \\
\hline & $(0.081)$ & $(0.175)$ & $(0.093)$ \\
\hline \multirow[t]{2}{*}{ Satisfacción con la democracia } & 0,444 & $-0,112 *$ & $-0,484^{*}$ \\
\hline & $(0.648)$ & $(0.190)$ & $(0.495)$ \\
\hline \multirow[t]{2}{*}{ Confianza partidos políticos } & 0,577 & 0,189 & $-1,709 * * *$ \\
\hline & $(0.461)$ & $(0,164)$ & $(0.210)$ \\
\hline \multirow[t]{2}{*}{ Interés por la política } & $-0,999$ & $0.856^{*}$ & $-0,631 * *$ \\
\hline & $(0.153)$ & $(0.031)$ & $(0,219)$ \\
\hline \multirow[t]{2}{*}{ Ideología } & $0,348 * * *$ & $-0,194 * *$ & $-0,451 * * *$ \\
\hline & $(0.048)$ & $(0,834)$ & $(0.155)$ \\
\hline \multirow[t]{2}{*}{ Cercanía partidos políticos } & $1.870 * *$ & $1.890 * * *$ & $2,082 * *$ \\
\hline & $(0.349)$ & $(0,456)$ & $(0,312)$ \\
\hline \multirow[t]{2}{*}{ Valoración situación económica } & $-0,432$ & $-0,999$ & $-0,438$ \\
\hline & $(0.475)$ & $(0,432)$ & $(1,193)$ \\
\hline \multirow[t]{2}{*}{ Valoración situación política } & $-0,567 * * *$ & $-0,432$ & $-0,101 * * *$ \\
\hline & $(0.399)$ & $(0.436)$ & $(0.775)$ \\
\hline \multirow[t]{2}{*}{ Valoración gestión gobierno } & -0.0134 & $-1,293$ & $-1.843 * *$ \\
\hline & $(0.156)$ & $(0.843)$ & $(0,685)$ \\
\hline \multirow[t]{2}{*}{ Constante } & 3,121 & 2,987 & 2,095 \\
\hline & $(2.121)$ & $(2.673)$ & $(2.1784)$ \\
\hline
\end{tabular}

Pseudo $\mathrm{R}^{2}=0,78$

$X^{2}(76$ grados de libertad $)=3.042,13 * * *$

El modelo recoge los coeficientes de regresión logística multinomial. Entre paréntesis, los errores típicos. Los niveles de significación estadística son: $* * *<0,001 ; * * \mathrm{p}<0,01 ; * \mathrm{p}<0,5$

Fuente: elaboración propia a partir del estudio postelectoral 2015 del Centro de Investigaciones Sociológicas. 


\section{CONCLUSIONES}

El sistema de partidos español ha mostrado hasta los años noventa signos de estabilidad, definiendo la competición política a través de la alternancia entre los dos partidos mayoritarios. Los anclajes electorales de los electores estaban definidos, destacando entre ellos la ideología. El descenso relativo de este elemento como consecuencia de la racionalidad en su comportamiento generó nuevos realineamientos electorales a mediados de los años 2000. Sin embargo, no es hasta la mitad del primer decenio del siglo actual cuando el sistema político muestra signos evidentes de cambios. El más singular es la presencia en la arena de competición electoral de nuevos partidos con capacidad suficiente para alterar la gobernabilidad del sistema. Partiendo de esta coyuntura, y de la premisa de que «las elecciones solo pueden ser estudiadas en sus propios contextos» (Montero y Lago, 2010: 18), este trabajo ha tratado de aportar luz sobre el comportamiento de los españoles en las elecciones generales de 2015. Estas elecciones abren un nuevo escenario político en el que confluyen nuevas dinámicas electorales. El contexto en el que se celebraron viene marcado por una serie de acontecimientos electorales que traslucían un cambio en las orientaciones electorales en la esfera subnacional que finalmente impregna el voto en las elecciones de 2015. Pero, además, si en elecciones generales precedentes la coyuntura económica determinó la orientación del voto e impulsó un voto de castigo sobre la base de la evaluación de la gestión gubernamental (Fraile, 2007), en 2015 las cuestiones de índole política parecen dominar en el ambiente político, situándose en el epicentro de las decisiones electorales. La política cuenta, y la combinación de la influencia de las estrategias, el discurso, las decisiones y las actuaciones de los partidos contribuye a la (re)creación y (re)activación de identificaciones y lealtades partidistas repercutiendo en la orientación del voto. Los datos de este trabajo evidencian que los electores han desarrollado vínculos con los nuevos partidos del sistema, en estrecha relación con las valoraciones del funcionamiento del sistema democrático y con la competencia electoral. Y, para ello, la proximidad ideológica se convierte en una herramienta útil para elaborar juicios y definir el voto a los partidos en escenarios de alta competitividad estructurando el electorado de los partidos políticos.

El trabajo vincula dos aspectos hasta ahora aislados desde un punto de vista empírico: la existencia de vínculos ideológicos con los partidos en un escenario competitivo y, por otro lado, el papel que desempeña la ideología en la conformación de los electorados de nuevos partidos de ámbito nacional. De este modo, este trabajo retoma la proximidad ideológica en el voto como un factor fundamental de la relación partido-votante en contextos competitivos. Aunque inicialmente los dos partidos nuevos en el escenario electoral, Podemos y Ciudadanos, no enfocaron su estrategia según la cuestión ideoló- 
gica, los votantes recurrieron a esta variable para orientar su voto. Pero ello no descarta la existencia de diferentes estrategias de vinculación para conectar ideológicamente con un electorado que toma en consideración el contexto político en el que se celebran las elecciones y que no vota bajo los supuestos de proximidad ideológica, lo que deja abiertas nuevas líneas de investigación que profundicen en las dinámicas desarrolladas por los partidos para captar y movilizar a electores próximos y no próximos ideológicamente. En definitiva, este análisis reconsidera el papel que la ideología desempeña en la estructura de las preferencias partidistas y su utilidad en términos electorales. Esperamos que este trabajo contribuya a desarrollar futuros análisis empíricos sobre el comportamiento de los españoles en un contexto multipartidista.

\section{BIBLIOGRAFÍA}

Budge, I.; Crewe, I. y Farlie, D. (eds.) (1976). Party identification and beyond: representations of voting and party competition. Londres: Wiley.

Campbell, A.; Gurin, G. y Miller, W. E. (1954). The voter decides. Evanston: Row and Peterson.

Campbell, A.; Converse, P. E.; Miller, W. E. y Stokes, D. (1960). The American voter. Nueva York: Wiley.

Converse, P. E. (1964). "The nature of belief systems in mass publics", en D. E. Apter (ed.), Ideology and discontent. Nueva York: Free Press.

- (1969). "Of time and partisan stability", Comparative Political Studies, 2: 139-171.

Converse, P. E. y Pierce, R. (1985). "Measuring partisanship", Political Methodology, 11: 143-166.

Dalton, R. J. y Wattenberg, M. P. (1993). "The not so simple act of voting”, en A. W. Finifter (ed.), Political Science: the state of the discipline II. Washington D.C.: The American Political Science Association.

Dalton, R. J., Flanagan, S. C. y Beck, P. A. (eds.) (1984). Electoral change in advanced industrial democracies: realignment or dealignment? Princeton: Princeton University Press.

Dassonneville, R. (2018). "Electoral volatility and parties' ideological responsiveness", European Journal of Political Research, 57(4): 808-828.

Delgado-Fernández, S. y Cazorla-Martín, A. (2017). "El Partido Socialista Obrero Español: de la hegemonía a la decadencia", Revista Española de Ciencia Política, 44: 247-273. 
Dennis, J. (1991). “The study of electoral behavior”, en W. Crotty (ed.), Political Science: looking to the future. Political behavior. Easton: Northwestern University Press, pp. 51-89.

Downs, A. (1957). An economic theory of democracy. Nueva York: Harper and Row.

Ersson, S. y Lane, J. E. (1982). "Democratic party systems in Europe. Dimensions, change and stability", Scandinavian Political Studies, 5: 67-96.

Evans, G. (ed.) (1999). The end of class politics? Class voting in comparative context. Oxford: Oxford University Press.

Feldman, S. y Johnston, C. (2014). "Understanding the Determinants of Political Ideology: Implications of Structural Complexity", Political Psychology, 35(3): 337-358.

Fiorina, M. (1977). "An outline for a model of party choice”, American Political Science Review, 21: 601-621.

- (1981). Retrospective voting in American national elections. New Haven: Yale University Press.

Fraile, M. (2007). "El voto por rendimientos: los temas económicos y sociales", en J. R. Montero, I. Lago y M. Torcal (eds.), Elecciones generales 2004. Madrid: Centro de Investigaciones Sociológicas.

Franklin, C. H. y Jackson, J. E. (1983). “The dynamics of party identification”, American Political Science Review, 77: 957-973.

Franklin, M.; Mackie, T. y Valen, H. (1992). Electoral change: responses to evolving social and attitudinal structures in Western countries. Nueva York: Cambridge University Press.

Fuchs, D. y Klingemann, H. D. (1990). "The left-right schema”, en M. Kent Jennings y J.W. van Deth et al. (eds.), Continuities in political action: a longitudinal study of political orientations in three Western democracies. Nueva York: De Gruyter.

Heath, A.; Jowell, R. y Curtice, J. (1985). How Britain votes. Londres: Pergamon.

Key, V. O. (1966). The responsible electorate. Cambridge: Harvard University Press.

Kitschelt, H. (2000). "Linkages between citizens and politicians in democratic polities", Comparative Political Studies, 33(6): 845-879.

Kitschelt, H. y Wilkinson, S. I. (2009). Patrons, Clients and policies. Patterns of democratic accountability and political competition. North Carolina: Duke University Press.

Lachat, R. (2008). "The impact of party polarization on ideological voting", Electoral Studies, 27 (4): 687-698.

Lazarsfeld, P. F.; Berelson, B. R. y Gaudet, H. (1944). The people's choice. Nueva York: Columbia University Press. 
Lipset, S. M.; y Rokkan, S. (1967). "Cleavage structures, party systems and voter alignments, an introduction", en Party systems and voters aligments. Nueva York: Free Press.

Manin, B.; Przeworski, A. y Stokes, S. C. (1999). "Elections and representation”, en A. Przeworski, S.C. Stokes y B. Manin (eds.), Democracy, accountability, and representation. Cambridge: Cambridge University Press.

Mattei, F. y Niemi, R. G. (1991). "Unrealized partisans, realized independents and the intergenerational transmission of partisan identification", Journal of Politics, 53: 161-174.

McClosky, H. (1964). "Consensus and ideology in American politics”, American Political Science Review, 58: 361-382.

Medina, L. E. (2004). La evolución de las identificaciones ideológicas En España sobre la base del esquema izquierda y derecha (1979-2000). Barcelona: ICPS.

Miller, W. E. (1991). "Party identification, realignment and party voting: back to the basics", American Political Science Review, 85(2): 557-568.

Montero, J. R.; y Lago, I. (2010). "Introducción: 2008, las décimas elecciones desde la restauración de la democracia”, en J. R. Montero e I. Lago (eds.), Elecciones Generales 2008. Madrid: Centro de Investigaciones Sociológicas.

Montero, J. R.; Gunther, R. y Torcal, M. (1998). "Actitudes hacia la democracia en España: legitimidad, descontento y desafección”, Revista Española de Investigaciones Sociológicas, 83: 9-49.

Newton, K. y Norris, . (2000). "Confidence in public institutions: Faith, culture, or performance?”, en S. Pharr y R. Putnam (eds.), Disaffected democracies: What's troubling the trilateral countries? Princeton, NJ: Princeton University Press.

Nie, N. H.; Verba, S. y Petrocik, J. R. (1979). The changing American voter. Cambridge: Harvard University Press.

Rose, R. y Unwin, D. (1970). "Persistence and change in Western party systems since 1945", Political Studies, 18(3): 287-319.

Rusk, J. G. y Norpoth, H. (1982). "Partisan dealignment in the American electorate: itemizing the deductions since 1964", American Political Science Review, 76: 522537.

Sani, G. y Montero, . R. (1986). "El espectro político: izquierda, derecha y centro" en J.J. Linz y J.R. Montero (eds.), Crisis y cambio: electores y partidos en la España de los años ochenta, Madrid, Centro de Estudios Constitucionales.

Thomassen, J. (1976). "Party identification as a cross-national concept: its meaning in the Netherlands", en I. Budge, I. Crewe, D. Farlie (eds.), Party identification and beyond. Londres: Wiley. 
Torcal, M. (2010). "Los anclajes del voto en las elecciones de 2008”, en J.R. Montero e I. Lago Peñas (eds.), Elecciones generales 2008, Madrid: Centro de Investigaciones Sociológicas.

Torcal, M. y Medina, L. (2002). “Ideología y voto en España 1979-2000: los procesos de reconstrucción racional e identificación ideológica”, Revista Española de Ciencia Política, 6: 57-96.

Toubeau, S. y Wagner, M. (2016). "Party competition over decentralisation: The influence of ideology and electoral incentives on issue emphasis", European Journal of Political Research, 55: 340-357.

Oesch, D. y Line, R. (2018). "Electoral competition in Europe's new tripolar political space: Class voting for the left, centre-right and radical right", European Journal of Political Research, 57(4): 783-807.

Sánchez-Cuenca, I. (2003). How can governments be accountable if voters vote ideologically? Madrid: Instituto Juan March de Estudios e Investigaciones, Working Paper 2003/191.

Van Deth, J. y Janssen, J. I. H. (1994). "Party attachments and political fragmentation in Europe", European Journal of Political Research, 25: 87-109.

Van der Eijk, C. y Niemöller, B. (1980). Electoral change in the Netherlands. Empirical results and method of measurements, Amsterdam: CT Press.

Verba, S.; Schlozman, L. K. y Brady, H. E. (1995). Voice and Equality. Civic Voluntarism in A,merican Politics. Cambridge, Mass.: Harvard University Press.

Weisberg, H. F. (1980). "A multidimensional conceptualization of party identification", Political Behavior, 2: 33-60. 